\title{
LA SEGUNDA GENERACION REPUBLICANA EN CUBA Y SUS FIGURAS PRINCIPALES
}

\author{
POR \\ ROSARIO REXACH \\ New York, N. Y.
}

Al proclamarse la República de Cuba el 20 de mayo de 1902, la generación vigente en el poder y en la vida nacional se encontró con un ambiente espiritual dominado por estos hechos. En primer término era, con mucho, una generación triunfante. Había seguido a Martí en su prédica y lucha libertadora y había luchado activamente en la «manigua». Y había triunfado porque, finalmente, tras más de treinta años de lucha, veía ondular en el Morro de La Habana la bandera nacional. Verdad es que esta independencia no era total. El apéndice añadido a la Constitución de 1901 y conocido como «enmienda Platt» mermaba considerablemente el sentimiento de euforia nacional por cuanto concedía a los Estados Unidos el derecho a intervenir en la vida del país cuando las circunstancias de inseguridad lo hiciesen aconsejable. Eso, lógicamente, teñía de un tono depresivo las esperanzas de la nueva nacionalidad, como lo acredita este fragmento de la composición «Mi Bandera», de Bonifacio Byrne (1861-1936), escrita en 1899 , al regresar el poeta de la emigración:
Al volver de distante ribera con el alma enlutada y sombría afanoso busqué mi bandera iy otra he visto además de la mía!
Aunque lánguida y triste tremola mi ambición es que el sol con su lumbre la ilumine a ella sola - $\mathfrak{i}$ a ella sola!- en el llano, en el mar y en la cumbre :

1 Bonifacio Byrne, el «poeta de la guerra». Composición: «Mi bandera». Véase Max Henríquez Ureña, Panorama histórico de la literatura cubana (Puerto Rico-México, 1963), t. II, p. 208. 
Y debe, además, consignarse que muchos de los cubanos integrantes de la Convención Constituyente de 1901 se opusieron a dicha adición con palabra enardecida y claros argumentos. Y destaco a Manuel Sanguily - uno de los mejores oradores de la época- y a Juan Gualberto Gómez, el fraternal colaborador y amigo de José Martí. Ese sentimiento de frustración fue, poco a poco, incrementándose y creando conciencia.

Pero aún otros factores actuaban en la vida espiritual del momento. Por un lado, la influencia del positivismo y cientificismo en boga había determinado que Enrique José Varona -al frente de los destinos culturales de la nación - determinase una modificación sustantiva del curriculum del bachillerato, suprimiendo el estudio de las lenguas clásicas en beneficiô del estudio de las ciencias. Y, en lo estrictamente literario, quedaba viva la enorme vigencia que en los campos de la creación había tenido el Modernismo y, principalmente, su figura señera, Rubén Darío. Pero como ocurre con todos los epígonos, esta modalidad sólo se hizo patente en lo más externo del movimiento, en lo más superficial y sonoro, en lo menos sustantivo.

Como consecuencia de esta atmósfera cultural, no es de extrañar que en esta primera generación republicana floreciesen a granel los poetas, los oradores muchas veces enfáticos, los argumentadores políticos que ventilaban sus cuestiones en el periodismo, usando por primera vez de una libertad de expresión antes no conocida. Eso explica que surgieran en la época multitud de diarios o periódicos que daban fe de los destinos nacionales ${ }^{2}$. Y como el pensamiento sereno y sosegado que requiere el ensayo interpretativo no era casi posible en la hora, fue la novela el género que plasmó entonces las inquietudes y vaivenes de la vida cubana. Y algunas fueron muy buenas. Inútil citar nombres, porque no es éste mi tema. Pero sí quiero recordar una $-\mathrm{y}$ no por sus valores intrínsecos-, sino porque muy gráficamente, en su título, simbolizó muy bien la entraña viva de aquella generación republicana. La novela es Generales y Doctores (1920). Su autor, Carlos Loveira.

No hay que ser zahorí para no ver en dicho título la lucha, sorda a veces, otras no tanto, entre las clases que vamos a llamar «intelectuales» - los doctores - y la generación que había peleado en la guerra y se sentía con derecho al poder. Pues no puede olvidarse que en los primeros años de la República dos generales de la guerra ocuparon la presidencia. Y que la tendencia persistió porque —cuando ya esta primera generación perdió

\footnotetext{
${ }^{2}$ Véase Max Henríquez Ureña, op. cit., t. II, pp. 257-261.
} 
su vigencia - todavía otros dos líderes de la Guerra de Independencia asumieron el mando nacional.

Sin embargo $-\mathrm{y}$ siguiendo la tesis de Ortega-, dicha primera generación republicana tuvo dos momentos. El inicial, de euforia, que culmina alrededor de 1910, y los epígonos, que se inician entonces. De ahí que en este segundo período se registren intentos de superar los estilos y modos vigentes en la cultura nacional. Los poetas evolucionan y tratan de superar el «rubendarismo» trasnochado, sustituyéndolo por un tono intimista y una poesía de mayor hondura. Figuras principales de esa tendencia fueron Regino Boti, José Manuel Poveda y Agustín Acosta. El tono oratorio y enfático de los primeros articulistas queda superado. Y aún aparecen algunos ensayistas como Jesús Castellanos.

Pero el sentimiento de frustración nacional se exacerba, la lucha por el poder se hace violenta - al menos en las palabras y aun en el campo armado- y los jóvenes que surgen pretenden -como siempre-- re-encauzar la vida del país. A dichos factores internos se suman dos hechos, ocurridos en el campo interamericano e internacional, que ejercieron enorme impacto en la vida cultural de Cuba. Fueron la Revolución mexicana de 1910 y la Revolución rusa de 1917.

En este clima de inconformidad - y aun rebeldía - se forja la segunda generación republicana, que es el tema que nos ocupa. Si la primera-de la cual he hecho una apretada síntesis - es una generación que en sus inicios se siente triunfante y segura, esta otra nace bajo un signo de profundo criticismo. Nada, para los jóvenes de entonces, era en Cuba como debía ser. Un profundo anhelo reformista, y más, revolucionario, la informaba. Y como se mantiene muy al tanto de lo que pasa en el mundo, se ve influida por las corrientes culturales que emanan de Europa, principalmente de París, y también por lo que pasa en Hispanoamérica, como el movimiento estudiantil de Córdoba, en la Argentina, entre otras influencias. Es decir, no es una generación enmarcada en los límites nacionales, sino una generación abierta a los cuatro vientos del espíritu. No implica esto un desasimiento de los destinos del país. Bien al contrario. Pero esta preocupación nacional va a tener como instrumentos ideológicos las nuevas ideas que en lo político y social han diseminado las dos revoluciones mencionadas, y en lo intelectual tomarán contacto vivo con los movimientos de que París es centro. $\mathrm{Y}$ aún debe añadirse algo más. La influencia que por entonces ejercieron en Cuba escritores, científicos y nuevas tendencias pedagógicas de los Estados Unidos, con John Dewey a la cabeza.

Con este conjunto de factores vigentes no es de extrañar que la segunda generación republicana se haga originar en un acto de franca rebeldía 
ocurrido en 1923 y conocido como la «Protesta de los Trece» ${ }^{3}$. En el fondo, actos de este tipo han ocurrido muchas veces sin que hayan dado base al comentario histórico o cultural. Lo que ocurrió en este caso es que la protesta de un grupo de jóvenes de excelente formación - al levantarse en ostentosa y rebelde actitud en un acto en que hablaba un ministro del Gobierno constituido- revelaba un estado de espíritu no presente antes de modo tan manifiesto. Dichos jóvenes procedían de un grupo que usualmente se reunía para discutir libros, ideas, nuevas empresas culturales, al amparo de una revista del gran público: la revista Social. Y que lo era porque en ella aparecía cuanto de valer ocurría en la sociedad cubana, con abundancia de ilustraciones gráficas y una excelente tipografía. Pero que sus directores - con muy buen tino- enriquecían con material literario de excelente calidad ${ }^{4}$.

El grupo mencionado es el que se conoce como Grupo Minorista. Lo integraban los jóvenes de entonces, mezclados a algunas figuras de la generación anterior que se habían distinguido por su amplia curiosidad, por su formación cultural, por su apetencia de una vida nacional más digna y más plena, por un indudable afán de servicio y por su admiración por libros y obras de arte que depuraran el estilo de la cultura en Cuba, enriqueciéndola. Dicho grupo se reunía en las oficinas de la revista mencionada, en el café Martí o en la de un abogado joven, Emilio Roig de Leuchsenring, cuyo despacho estaba céntricamente situado. Y cuando pasaban por La Habana intelectuales de renombre los agasajaban con un almuerzo en un restaurante también muy al alcance de todos los participantes: el Lafayette. Los integrantes del Grupo Minorista fueron muchos, como puede verse en la nota consiguiente. Pero es imperativo decir que de la nómina del grupo surgió lo que puede llamarse «la intelectualidad» de la generación. En lo fundamental fueron ensayistas. Se explica. Todos habían leído ampliamente a Ortega y Gasset, a Unamuno y también a Eugenio d'Ors. Además, estaban suscritos a El Espectador y leían las

${ }^{3}$ Los «trece» fueron: Rubén Martínez Villena, Jorge Mañach, Félix Lizaso, Juan Marinello, Francisco Ichaso, Luis Gómez Wangüemert, José Manuel Acosta, José Zacarías Tallet, Primitivo Cordero, José Antonio Fernández de Castro, Alberto Lamar Schweyer, José García Pedrosa y Calixto Masó. Procedían todos del llamado "Grupo Minorista», que incluía, además, a Emilio Roig de Leuchsenring, Eduardo Abela, Dr. Juan Antiga, Diego Bonilla, Mariano Brull, Alejo Carpentier, Antonio Gattorno, Max Henríquez Ureña, Armando Maribona, Guillermo Martínez Márquez, Andrés Núnez Olano, Alfredo T. Quílez, Arturo Alfonso Roselló, Luis A. Baralt, Enrique Serpa, Juan José Sicre, Jaime Valls, Orosmán Viamonte y Roberto Agramonte. Dicho grupo suscribió un manifiesto que -puede decirse- fue el programa de la generación. Véase nota sobre la Revista de Avance.

${ }^{4}$ La revista Social fue fundada por Conrado Walter Massaguer - excelente caricaturista-. Y formó parte de su redacción Alfredo T. Quílez, ya nombrado. 
excelentes traducciones con que la Revista de Occidente ponía a los principales pensadores y literatos de otras lenguas a la disposición del público de habla española. En general, los miembros de este grupo se destacaron en el campo de las letras y del pensamiento, de las ciencias y de la política. Se mantenían abiertos a toda nueva idea y a toda innovación estética. De dicha actitud surgió un nuevo enfoque, no sólo en lo literario, sino en las artes plásticas, en la música, en el teatro y aun en la política. Pues dicha generación se planteó la tarea de la eliminación de la «enmienda Platt», lo que finalmente consiguió.

El clima espiritual que generó este movimiento dio origen a instituciones de todo tipo, que encarnaban la nueva actitud y que pretendían llevar a vías de hecho las nuevas ideas en todos los campos. Así surgieron instituciones y organizaciones que quedarán por siempre en los anales de la vida y la cultura en Cuba. Y nombro algunas: la Sociedad Pro-Arte Musical, creadora, antes de la Revolución última, del Ballet Nacional de Cuba y auspiciadora de la brillante ballerina Alicia Alonso; el Lyceum, que inauguró la primera sala de exposiciones abierta a los artistas adheridos a las nuevas normas estéticas, y que ofreció su tribuna a cuanto intelectual de valer pasaba por La Habana, y también a los nacionales; el Patronato de Artes Plásticas; la Institución Hispano-Cubana de Cultura, debida al celo de don Fernando Ortiz; el Patronato del Teatro; la Alianza Nacional Feminista, que propulsó el voto para la mujer y que lo obtuvo, y en fin, muchas otras que tanto en La Habana como en el interior, poco a poco, fueron rebasando el provincianismo que hasta entonces regía la vida cultural y nacional.

Como toda nueva generación, ésta también quiso tener su órgano de difusión. Si la primera generación republicana lo había tenido en la revista Cuba Contemporánea, ahora se imponía un nuevo tipo de publicación. Una revista que no se anclase en el pasado, sino que mantuviese alerta la conciencia a todo nuevo enfoque y que, para hacerlo, tendría que inspirarse en un total sentido de renovación. Y tanto pudo dicho espíritu en sus editores, que muy ingenuamente - dicho sea de paso - pretendieron que esa publicación careciese de nombre fijo, y la nombraron inicialmente con el del año en que surgieron a la luz: 1927, con la íntima convicción de continuar la tradición novedosa nombrando las demás 1928, 1929, 1930. No pudieron llegar a más. Las causas son bien conocidas. Pero, por supuesto, es difícil la identificación de cualquier hecho sin darle un nombre fijo. De ahí que dicha publicación haya pasado a la historia con el subtítulo que aparecía bajo la fecha del año y que rezaba en letra minúscula —un acto más de rebeldía - como revista de avance. Fueron sus editores y propulsores -inicialmente- Jorge Mañach, Juan Marinello, Francisco 
Ichaso, Alejo Carpentier y Martí Casanovas. Posteriormente, los dos últimos fueron sustituidos - al haberse marchado del país a causa de motivos políticos- por José Zacarías Tallet y Félix Lizaso, quienes mantuvieron hasta el final su participación.

La Revista de Avance cumplió con creces sus promesas de mantener al día, en lo cultural, la conciencia nacional. Por sus páginas desfilaron nombres hasta entonces desconocidos de la gran mayoría. Ortega y Gasset, Unamuno, García Lorca, Dámaso Alonso, Valéry, Picasso, Juan Gris y tantos más, así europeos como hispanoamericanos o norteamericanos, se dieron a conocer y muchos de ellos enviaron a la revista trabajos inéditos. También la revista fue vehículo abierto a los nuevos escritores, y Regino Pedroso, Mariano Brull o Lino Novás Calvo - entre otros - publicaron en sus páginas, descontando la importante contribución de sus editores. Venía, además, ilustrada con excelentes dibujos de algunos de los pintores mencionados, además de los del patio, como Gattorno, para citar sólo uno, aunque no el de más valer. Pero no es el tema de hoy dicha revista. Hay ya muchos trabajos sobre ella y remito a los interesados a su lectura ${ }^{5}$. Ahora sólo me resta decir que este trabajo se centrará en cuatro de sus colaboradores, con breves noticias de algunos otros escritores de la generación que merecen cita.

Pero antes de entrar a discutir dichas figuras es bueno hacer una apreciación de conjunto sobre lo que esta generación produjo. Si la primera generación se ocupó principalmente de la oratoria, de la poesía y la novela y, en gran parte, del artículo periodístico de contenido político o social en alguna medida-, esta nueva generación, por su formación y sus inquietudes, va a ser una generación de ensayistas. No quiere esto decir que no hubiese en ella poetas. Claro que los hubo, y de gran resonancia por las innovaciones que introdujeron en la poesía, tanto en la forma como en la emoción y los temas poéticos que la informaban. Baste a este fin citar estos nombres impares: Mariano Brull, Emilio Ballagas y Eugenio Florit, a los que se pueden añadir los de Nicolás Guillén, José Zacarías Tallet, Regino Pedroso y lo mejor de Rubén Martínez Villena.

El hacer poético que los más importantes propulsaron y ejemplificaron rebasó ya los linderos del Modernismo, para internarse por otros caminos poéticos, cuya más distante inspiración sería Paul Valéry.

En cambio, la novela tiene en esta generación relativamente poca importancia, como muy bien lo ha señalado Max Henríquez Ureña al escribir:

${ }^{5}$ Véase Rosario Rexach, «La Revista de Avance (1927-1930)», en Caribbean Studies, núm. 3 (octubre 1963). Fue éste el primer estudio publicado sobre dicha revista. Después han venido otros. Deben destacarse los de Carlos Ripoll y César Leante, entre varios. 
Así como ha cobrado auge en Cuba la producción de cuentos, que hasta fines del siglo XIX era escasa, ha disminuido la de la novela, una vez cerrada la etapa de la primera generación republicana ${ }^{6}$.

Pero hay un tema que absorbe, en todos los sentidos, a esta segunda generación. Dicha falange histórica está convencida de que el gran líder de la independencia, José Martí, es todavía un desconocido. Había sido, es cierto, la figura máxima de la lucha independentista. Pero había vivido casi toda su vida adulta fuera de Cuba y — salvo raras muestras - su obra había aparecido en los Estados Unidos, en los periódicos de Hispanoamérica o alguna vez - muy al principio- en España. ¿Cómo pedir, pues, al cubano que conociese su obra? La generación anterior - tal vez no por falta de seriedad o interés, sino de fuentes - lo citaba sólo por fragmentos de discursos o por la memoria de sus hechos. Algunos esfuerzos se habían realizado para darlo a conocer. Es cierto. Pero, repito, Martí, el real Martí, no era conocido en su obra ni en su vida. La segunda generación republicana se impuso la tarea de enmendar el fallo. Es verdad que la obra del gran cubano estaba íntegra en las manos de su albacea literario y leal discípulo Gonzalo de Quesada, que la atesoraba y que se había impuesto la tarea de su publicación, que luego continuaría su hijo Gonzalo de Quesada y Miranda. Pero ello requería recursos y tesón. Quesada trataría de procurarse los recursos. El tesón lo tenía. El Grupo Minorista, con los mejores de sus miembros al frente, coincidía en el propósito. Así nació la Editorial Trópico, que se dio a la tarea de la publicación de los papeles del héroe. Setenta y cuatro tomos llegó a publicar. Y hasta la edición del cincuentenario de la muerte de Martí, en 1945, debida al celo de esos dos españoles excepcionales que fueron don Mariano Sánchez Roca y Rafael Marquina, fueron dichos tomos la fuente única donde pudieron los cubanos conocer no sólo la obra del patriota, sino del escritor. Esto determinó un amor por la figura y la obra de Martí sin precedentes en la historia de Cuba. Bien lo reconoció Juan Marinello al escribir: «A Martí no se le puede leer sin contagio, y el que lo lea sin sentirse parte de su temblor, no lo ha leído, aunque haya pasado bajo los ojos todas sus páginas» ${ }^{7}$.

Se hacía necesario, pues, poner en claro la biografía del gran hombre. A la tarea se aplicaron muchos, desde Alfonso Hernández Catá o Luis Rodríguez Embil hasta Jorge Mañach con su Martí, el Apóstol (1933) o Félix Lizaso con Martí, místico del deber (1940); sin olvidar las de Manuel Isidro Méndez o la de Carlos Márquez Sterling, entre otras.

${ }^{6}$ Max Henríquez Ureña, op. cit., p. 405.

7 Juan Marinello, Once ensayos martianos (Comisión Nacional Cubana de la UNESCO, 1964), pp. 25-26. 
La generación había cumplido su promesa. Si durante la primera, Martí había sido un «ilustre desconocido», como lo llamó Ventura García Calderón, ya después sería una figura prócer que había que leer y que había dónde leerlo, más allá de toda antología, que si rinden a veces una función, la mayoría impiden llegar a las fuentes y cultivan la superficialidad en la cultura.

Hechas estas aclaraciones y puntualizaciones, vamos a señalar las figuras de quienes nos ocuparemos en este trabajo. Son ellas: JORGE MAN̈ACH, Juan Marinello, Francisco Ichaso y Félix Lizaso. Todos, por rara coincidencia, coeditores de la Revista de Avance. Pero antes de entrar en ello, permitáseme decir que hay otros muchos miembros de esta generación que merecerían figurar. Para mí, sobre todo, Medardo Vitier, José María Chacón y Calvo y Roberto Agramonte.

Al primero se le conoce poco fuera de los límites de Cuba, pese a haber editado algunas de sus obras en importantes editoriales de Hispanoamérica. $\mathrm{Y}$ es, en cierto modo, injusto ese desconocimiento. Y no creo que sea intencionado. Lo que ocurre es que Vitier no era de La Habana y su formación había ocurrido en provincias. Además, era hombre por demás modesto e introvertido, poco dado a la sociabilidad expansiva frecuente en los círculos intelectuales. Pero tenía una cultura sólida, una muy buena formación filosófica y dejó una obra que hay que valorar en el plano del pensamiento cubano. La figura que, tal vez, más admiró en nuestra historia fue la de Enrique José Varona, al que dedicó páginas memorables. Además es autor de un excelente libro, Las ideas en Cuba (1938), y de otro titulado La filosofía en Cuba (1948). Fue colaborador asiduo del Diario de la Marina en una columna titulada «Valoraciones». En los inicios de su labor como escritor publicó un pequeño libro, esta vez de literatura, titulado Apuntes literarios (1935). Y sustituyó en el Ministerio de Educación al doctor Jorge Mañach, quien, por razones políticas, había marchado a Nueva York, donde inmediatamente comenzó a enseñar en la Universidad de Columbia. Y debe decirse que en dicha posición mantuvo los lineamientos culturales que había programado Mañach.

En cuanto a José M. Chacón y Calvo - también de esa generación, aunque se había destacado desde antes-, no necesita ser dado a conocer. Su vasta labor de investigación y crítica literaria está bien acreditada sobre todo después de los estudios de Zenaida Gutiérrez-Vega. Y alguna mención debe hacerse de don Fernando Ortiz, gran animador de la cultura, pero dedicado especialmente a los estudios antropológicos. Y junto a él no debe olvidarse una figura femenina de gran resonancia, Lydia Cabrera, a la que se conoce no sólo por sus estudios antropológicos, sino por su obra literaria y por sus conexiones con figuras tan notables como Teresa de la Parra y 
Gabriela Mistral y cuyos Cuentos Negros en Cuba celebraron en 1986 su cincuentenario con la publicación del recuento titulado: En torno a Lydia Cabrera, Miami, 1987.

Y Roberto Agramonte (1904) ha sido un profesor ilustre que se ha destacado en los estudios psicológicos y sociológicos. Pero a quien es ineludible recordar por sus muy acabados estudios sobre Juan Montalvo y sobre José Martí. Trabajador infatigable, investigador de gran seriedad, la obra de Roberto Agramonte merece un estudio serio que algún día se hará para situarlo como una de las personalidades más destacadas de la segunda generación republicana.

Dicho lo anterior, pasemos a las figuras mencionadas. Sea la primera JoRge MañaCH (Cuba, 1898; Puerto Rico, 1961).

Fue Mañach hombre de formación académica seria. Parte de su niñez y adolescencia transcurre en España. La formación académica de su juventud la obtiene en Massachusetts, donde se gradúa en Harvard (1921) y obtiene una beca de eminencia para estudiar en París. Sólo un año puede permanecer allí y regresa a La Habana - por motivos familiares-, donde completa sus estudios de Derecho y de Filosofía y Letras.

Desde muy joven se sintió atraído por la letra escrita. Muy pronto, estando en París, inició sus tareas periodísticas, enviando algunas colaboraciones al Diario de la Marina, donde actuaba como uno de los directores don León Ichaso. Y desde su regreso a Cuba ese menester no cesó. Fruto de ello son los libros en que reunió los artículos que mejor estimó. El primero, Glosario (1924)... Y después, Estampas de San Cristóbal (1926), una serie de viñetas de la vida habanera que, en muchas ocasiones, logran gran fineza de expresión y hasta un sentido vagamente poético. Luego aparecería otra colección, Pasado vigente (1939), donde los temas tratados son indicio ya de los sentimientos y preocupaciones del escritor. Destaco, entre ellos, uno titulado «Martí non-nato», en donde se perfila la idea del desconocimiento del líder que tanto acució a su generación y que él intentó superar con el esfuerzo que representó la escritura de su biografía, Martí, el Apóstol, 1933. Se ha criticado mucho dicha biografía, pese a sus méritos, a los elogios y a sus múltiples ediciones. Se ha dicho - y no como valorque es «novelada». También que carece de sólida documentación. Documentación que no falta, por supuesto, pero que es mucho más evidente en la obra de Lizaso Martí, místico del deber. Se olvida, sin embargo, que median siete años entre ambas obras. Siete años que en alguna medida se multiplican, si se tiene en cuenta que, cuando la obra de Lizaso apareció, ya muchos nuevos papeles del héroe se habían publicado y muchos nuevos hechos habían salido a la luz, con la suficiente distancia histórica para 
aquilatarlos y estructurarlos. Entre una y otra biografía media sólo este hecho: en la época en que Mañach la escribió, Martí era todavía el «ilustre desconocido". Cuando la de Lizaso aparece es ya una figura claramente delineada en el trasfondo cultural de Cuba. Por eso es tan correcto el juicio de Andrés Valdespino, que en mucho compartieron Medardo Vitier y Gabriela Mistral, cuando escribió:

Mañach hace vivir a Martí como un ser de carne y hueso, con sus sueños y sus ilusiones, sus conflictos íntimos y sus frustraciones públicas y privadas, sus preocupaciones patrióticas y sus pequeños dramas sentimentales. $\mathrm{Ni}$ Mañach trata de ocultar su admiración por Martí ni de disimular la excepcional grandeza de aquella vida. Pero es fácil percibir su empeño por evitar que lo admirativo se convierta en actitud idolátrica ${ }^{8}$.

No vale, pues, una biografía más que otra. Las dos son excelentes y merecen lectura cuidadosa, si se pretende llegar a la hondura del hombre que fue José Martí, como es imprescindible para ello la de Manuel Isidro Méndez o la de Carlos Márquez-Sterling. Todas colaboran a una mejor comprensión del gran hombre.

Pero sigamos con Mañach. Pese a su quehacer periodístico, a sus menesteres políticos y a su labor docente en la Universidad de La Habana como profesor de Historia de la Filosofía, los altos temas de la cultura y el pensamiento acerado sobre los problemas cubanos no daban tregua al escritor que fue Mañach. Así se desdobló pronto en conferenciante y ensayista. En la Revista de Avance apareció gran número de sus ensayos de la época. Quizá el más importante sea, por cuanto reflejaba el espíritu del momento, el titulado "Vanguardismo", en donde, con gran sentido crítico y esmerada información, discute lo que entonces se denominaba «arte moderno» o «arte de vanguardia». Valdespino, al juzgar este ensayo, dice:

Ya desde este trabajo, escrito en plena juventud (1927), el autor manifiesta esa tendencia, tan propia de su personalidad, a rehuir los extremos y tratar de situarse en el justo medio. En la contienda literaria entre lo nuevo y lo tradicional, Mañach defiende el nuevo arte, pero censura la furia iconoclasta de muchos de sus representantes ${ }^{9}$.

Tiene razón el crítico. El escritor que fue Mañach tenía una filosofía acerca de la cultura y de la vida que poco a poco irá madurando, pero que ya está presente en sus primeras obras.

Además de esa labor ensayística que aparece en la Revista de Avance,

\footnotetext{
${ }^{8}$ Andrés Valdespino, Jorge Mañach y su generación en las letras cubanas (Miami, 1971), p. 135.

${ }^{9}$ Ibid., p. 149.
} 
pronto se reveló Mañach como conferenciante de rara calidad. Tenía para ello condiciones no comunes. Un perfecto dominio de la lengua, una capacidad singular para las grandes síntesis sin dejar de ser profundo, una cultura bien cimentada y continuamente ampliada, además de una voz bien modulada que sabía manejar a la perfección. No extrañe por eso que su primera conferencia en la Sociedad Económica de Amigos del País haya sido un verdadero acontecimiento cultural, al punto que fue publicada como homenaje a su autor. Se titulaba «La crisis de la Alta Cultura en Cuba» (1925). En ella proponía, después de un análisis cuidadoso, medios para superarla. Medios que, sin embargo, intentó llevar a la práctica al ocupar por breve espacio de tiempo la Secretaría de Educación, al crear la Dirección de Cultura, que luego regentarían Chacón y Lizaso. Otra conferencia de larga recordación es la que tituló Indagación del Choteo, 1928 , estudio fenomenológico-social de esa modalidad del carácter cubano. Así, lentamente, se fue forjando el gran ensayista y conferenciante que fue Jorge Mañach. Sus ensayos responden a tres esferas espaciales. Los ensayos de juventud se centran principalmente en su ambiente insular, con sus trabajos sobre Martí, muy numerosos, incluidos. Y culmina esta etapa con sus dos discursos de ingreso a la Academia de la Historia y a la Academia Nacional de Artes y Letras, titulados: «La nación que nos falta» $\mathrm{y}$ «El estilo en Cuba». Fueron recogidos posteriormente en libro con un artículo intercalado: «El estilo de la Revolución», primer premio en la serie del Premio Justo de Lara. Después rebasará la esfera nacional y se ocupará preferentemente de temas hispanoamericanos. De ello son buena muestra los publicados en la Revista Hispánica Moderna y en la revista Cuadernos, de París, así como en otras publicaciones más allá de las fronteras de su Isla. Ya en su última madurez se ocupó con asiduidad de temas españoles. El Examen del quijotismo (1950), escrito con motivo del cuadricentenario de Cervantes y que - en cualquier latitud y dentro de todas las conmemoraciones que entonces se publicaron- quedará por sus méritos en muy buena posición. Es un estudio profundo, serio, que presenta una nueva óptica sobre la obra cervantina. También de esta última madurez quedan sus entrevistas y estampas españolas reunidas en el tomo Visitas españolas. Y su último gran esfuerzo de pensamiento: su Teoría de la frontera, que excelentemente prologó Concha Meléndez. Se intenta en el libro un estudio a fondo de la repercusión cultural de toda frontera entre dos modos diversos de ver la vida. En este caso, la frontera a que se aplica el estudio es la frontera entre el mundo del norteamericano y el del hispanoamericano, ilustrando la tesis con su experiencia de Puerto Rico. Es un libro que requiere meditación, aunque, repito, quedó inconcluso. La muerte lo cercó antes de terminarlo. 
Pero Mañach no sólo fue ensayista, sino un buen conferenciante como ya se ha dicho. Era, por tanto, figura invitada regularmente por las principales instituciones culturales. A dicha actividad prestaba cuidadosa atención y preparaba sus disertaciones con esmero, desde la información de que se asistía hasta la originalidad del punto de vista y el estilo en que las escribía y pronunciaba. A veces se constituían en ciclos. Y, las más, tenían tal calidad, que se le instaba a la publicación. Sería tarea vana, por lo imposible, reseñar todas las que dio en su vida. Pero sí quiero destacar aquí la que ofreció en el Lyceum de La Habana con el título «Para una Filosofía de la Vida». Fue de gran impacto y se recogió después en un libro con el mismo título (1951), que, además, incluía otros trabajos, entre los cuales merece mención aparte el rotulado «Trinidad de Goethe», con motivo del bicentenario de su nacimiento. Es un trabajo en que el escritor revela su profundo conocimiento de la literatura y de la filosofía y los hermana para dar en apretada y casi poética síntesis una visión a profundidad del autor del Werther.

Este libro, además, es importante porque en él expone Mañach muy explícitamente su concepción del hombre y de la vida y postula su filosofía personal llamándola «condicionalismo». Concepto que define así:

Lo que llamo CONDICIONALISMO (sic) no es sólo esa concepción bipolar de los valores; es también la idea implícita —que no puedo sino sugerir aquí- de que todo el destino humano inteligible, todo lo que el hombre puede llegar a ser y a hacer, estriba en un progresivo y recíproco condicionamiento entre el objeto y el sujeto integrales, entre la totalidad del hombre y la totalidad del mundo.

Y continúa más adelante: «Se dirá que esto es una utopía. Claro que lo es. Pero el mundo ha caminado siempre hacia lo utópico y por la atracción de lo utópico» ${ }^{10}$. Por supuesto, los párrafos copiados, resumen de la tesis que el autor ha ido desarrollando despaciosamente, no pueden dar siquiera una vaga idea de la riqueza conceptual ni de la sensibilidad humana que hay en este estudio que merece ser más conocido.

Finalmente, debido a su profundo respeto por todas las formas culturales y por la libertad, fue Mañach un gran animador de toda empresa que tendiese a elevar la cultura de su pueblo. Y ahí están sus creaciones con dicho propósito: la «Universidad del Aire», que se radiaba cada domingo con ciclos de conferencias alrededor de un tema y a las que se invitaba a los especialistas más connotados a participar. También en su programa televisado «Ante la Prensa», donde solían debatirse los grandes problemas

\footnotetext{
10 Jorge Mañach, Para una filosofía de la vida (La Habana, 1951), pp. 91-92.
} 
televisado «Ante la Prensa», donde solían debatirse los grandes problemas nacionales siempre que hubo la posibilidad de hacerlo con plena libertad. No debe pasarse por alto que en su primera juventud se sintió tentado por el teatro y escribió una pequeña obra, Tiempo muerto, que obtuvo un segundo premio en un concurso. También escribió una novela, Belén, el Aschanti, que nadie ha podido rescatar hasta hoy.

Se impone, ahora, un breve comentario. Parcamente - como debe ser todo juicio contemporáneo- puede decirse que fue Jorge Mañach, dentro de la segunda generación republicana, una de sus figuras más señeras, si no la más. Su prosa excelente, su estilo fluido y al mismo tiempo profundo, su amor a Cuba y a los valores de dignidad, libertad y justicia están patentes siempre en su obra, que algún día tendrá merecido lugar entre los próceres latinoamericanos.

Vamos ahora a la figura de Juan Marinello (Cuba, 1899-1979). Pertenecía Marinello a una de las familias más preclaras de la región de las Villas en Cuba. Tuvo una educación esmerada y estudió en la Universidad de La Habana las carreras de Derecho y de Filosofía y Letras. Por muy breve tiempo fue instructor en la Facultad de Derecho. Pero la mayor parte de su vida fue profesor de Lengua y Literatura Española y Cubana en la Escuela Normal de Maestros de La Habana. Y en sus últimos años volvió a la enseñanza universitaria. Era una personalidad de extraordinario atractivo. Contaba para ello con su exquisita formación, debida no sólo a sus estudios, sino a sus viajes, a su conocimiento de varios idiomas y también a su exquisita sensibilidad y buenas maneras. Era todo un caballero. O, más apropiadamente, un gentleman, con la intensificación de matiz que el vocablo representa.

Su sensibilidad, a diferencia de la de Mañach, era menos inclinada a la lógica y más a lo poético. Y tanto es así, que lo atrajo siempre más la literatura que la filosofía, y más la poesía que el ensayo de estricta estructura lógica. Sin embargo, fue un gran ensayista. Podía serlo. Pues dominaba la lengua con rara perfección, y con su sensibilidad y su gran cultura —que siempre se preocupó de enriquecer- podía emitir juicios y elaborar sus tesis con gran maestría de expresión. Era también excelente conferenciante, a lo que colaboraba su voz de pausado timbre y matizada modulación. Como ya se ha dicho, fue uno de los editores de la Revista de Avance, a cuyo grupo estuvo perfectamente integrado, compartiendo deberes y responsabilidades. Tenía, además, un raro equilibrio para no caer en los extremos, aunque en lo político se adhiriese, pasada su primera juventud, a las tesis más extremistas de la izquierda. Pero no debe ser ése el tema que aquí se discuta, sino su hacer intelectual. Es a lo que se va.

Muy pronto en su vida se sintió Juan - como todos lo llamaban- 
tentado por la letra escrita. Ya en 1927 sale su primer libro, Liberación. Contra lo que pudiera suponerse por el título, no es libro que roce, siquiera de lejos, el tema político. Es un libro intimista, de poemas, en que la poesía es el ángel liberador. De ahí su nombre. En él logra Marinello aciertos poéticos que nadie debe desconocer. No es éste un trabajo de crítica, pero destaco que en esta obra el alma de poeta que había en Marinello transparece en muchas de sus páginas. Como muestra véase este poema:

\author{
LA NOCHE \\ ¿Por qué han hecho triste a la Noche \\ los ciegos poetas románticos? \\ La Noche es fiesta en el espíritu, \\ porque a su sombra luminosa \\ se presiente el Gran Salto. \\ En cada sombra redentora \\ hay algo de lo que vendrá. \\ (Esta mano de tierra no lo sabe decir; \\ esta lengua de tierra no lo sabe callar.) \\ Pero duele en la noche \\ sobre todas las cosas, \\ como un temblor de alas inexpertas \\ que se aprestaran a volar ${ }^{1 !}$.
}

Fácil discernir en el poema copiado la influencia de los nuevos modos poéticos propulsados por adheridos a las nuevas tesis.

Después de Liberación, sólo ocasional y muy esporádicamente volvió el escritor a la poesía y no insistió en reunirlas en libro. En cambio, sí publicó numerosos ensayos, al principio comentando temas poéticos, como es el caso de su libro Poética, ensayos en entusiasmo, publicado en Madrid en 1933. Dicho libro se estructura en torno a la crítica de cuatro poetas de la época, dedicando un pequeño comentario a cada uno en capítulos diferentes y tomando como base un solo poema, menos en el caso de Emilio Ballagas. Los cuatro poetas son, además de este último: Eugenio Florit, Manuel Navarro Luna y Nicolás Guillén. En el que enjuicia a Florit, con motivo de un poema aparecido en su libro Trópico, se permite aconsejar al poeta se separe de la tendencia de la llamada "poesía pura» al escribir:

\footnotetext{
${ }^{11}$ Juan Marinello, Liberación (Madrid, 1927. Poemas), pp. 87-88.
} 
Todo esto quiere decir, Eugenio Florit, que buena parte de los poetas hoy quieren entrar por puertas falsas en la nueva edad. Se quiere hacer poesía de nuevas palabras, no de nuevas esencias que tiñan reciamente a la palabra sometida ${ }^{12}$.

Sin embargo, en el ensayo se dicen cosas mucho más positivas, como cuando escribe: «... sigamos, sobre estas décimas bruñidas con sol y agua, el largo monólogo... Diálogo, mejor que monólogo; porque entre las puntas verdes de estos versos nuevos está padeciendo, y gritando su padecer gozoso, lo mejor de Eugenio Florit» ${ }^{13}$.

Sorprende la contraposición de ambos juicios. Hay una explicación: Marinello, entremezclado en las luchas políticas y ya muy inclinado hacia la izquierda, muestra en este libro la sutil evolución que hubo en su pensamiento, que determinaba su rechazo de la «poesía pura» y su preferencia por una más adscrita a lo real, como se demuestra en sus juicios sobre un poema de Navarro Luna aparecido en Pulso y Onda, donde dice, por ejemplo: «... al leerlos hemos visto removerse nuestra tierra escondida. Es que en ella estaba clavada ya la raíz estremecida de estos versos. Todo aquí es nuestro» ${ }^{14}$. Algo similar puede apreciarse cuando comenta el poema «El velorio de Papá Montero», de Guillén. En cambio, el juicio sobre Júbilo y fuga, de Emilio Ballagas, y que sirvió de prólogo al libro, mantiene la altura poética y crítica a que podía llegar Marinello cuando los garfios de la ideología no lo aprisionaban.

Sin embargo - como todos los de su generación-, también él cayó bajo el influjo fascinante de Martí, según ya se ha visto, y su devoción por el grande hombre fue tanta, que nunca pudo obnubilársele el juicio - como en tantos otros- al hablar sobre su obra, y lo hizo muchas veces. Prueba de ello son estas frases:

Mil veces hemos visto cómo los propagadores de la enseñanza confesional entre nosotros mechan sus sermones y comentarios con sentencias martianas. Lo que es tan desleal como querer adscribir a nuestro hombre al pensamiento marxista ${ }^{15}$.

Imbuido por la admiración al apóstol de nuestra independencia, gran parte de la escritura de Juan Marinello gira alrededor de la figura del prócer. Lo había leído toda su vida amplia y profundamente y lo conocía

\footnotetext{
12 Juan Marinello, Poética, ensayos en entusiasmo (Madrid, 1933), p. 43.

${ }^{13}$ Idem, p. 21.

14 Idem, p. 74.

15 Juan Marinello, El caso literario de José Martí. Motivos de centenario (La Habana, 1954), p. 26.
} 
como pocos. Por eso fue tan justo que al hacerse la edición completa de la obra de José Martí, en más de veinticinco tomos, en la Cuba de hoy, se encargasen a él las palabras prologales. Realizó su tarea con la responsabilidad y saber que tenía, y lo hizo admirablemente, descontando las frases de ritual a que le obligaban las circunstancias. Pero de todo lo que Marinello escribió sobre Martí, a mí una de las cosas que más me gusta es una pequeña edición en francés de presentación de la figura a los pueblos de esta lengua. Dicho trabajo está hecho con el esmero crítico habitual. También con alteza de miras y gran serenidad en la prosa, que, a ratos, alcanza el nivel poético, lo que no es extraño en quien ahogó en sí la poesía en aras de sus sentires políticos. Una ficha del libro aparece en las notas ${ }^{16}$.

Añádase a lo dicho que — como consecuencia de sus viajes y afanes políticos- Marinello publicó algunos libros. Uno es Viaje a la Unión Soviética y a las democracias populares, colección de artículos periodísticos (1950) que apenas trascendió el ámbito de los participantes de su ideología. Y, entre otros, cuenta en su haber una breve Historia de la Literatura Hispanoamericana, publicada en México en 1937. Y numerosos ensayos sobre Martí y otros temas, según ya se ha dicho. Resumiendo, ¿qué juicio debe emitirse con respecto a Marinello? Muy brevemente, como cuadra a este trabajo, éste: Fue un miembro eminente de la segunda generación republicana, con grandes méritos como ensayista y ocasional poeta. Su prosa era fluida, elegante, y su cultura tan sólida como su dominio de la lengua. Y sólo hay que lamentar que su entrega a los menesteres políticos lo sustrajeran a la labor cultural a que estaba llamado por su talento y su sensibilidad. Pero tal vez hay quienes crean que hizo lo que debía. Quizá él mismo lo creyó. Frente al dilema, debe callarse y seguir.

La próxima figura a que nos acercaremos es la de FRANCISCO ICHASO MaCías (Cuba, 1900; México, 1962).

Francisco Ichaso, hombre de expansiva y abierta cordialidad, de una exquisita sensibilidad estética, muy inteligente y con una cultura muy cimentada, ampliada por su dominio de varios idiomas, era graduado de la Universidad de La Habana. Pero su decidida vocación fue la letra impresa, y en menor grado la política. Tenía de quién heredar su amor a las letras, pues su padre, don León Ichaso, fue uno de los directores del Diario de la Marina y un connotado periodista. Por eso, desde muy joven, Paco

\footnotetext{
${ }^{16}$ Juan Marinello, José Martí (Poètes d'aujourd'hui) (París: Colección Seghers, 1970). Traducción de René L. F. Durand.
} 
- como todos le llamaban- se dio a escribir. Por supuesto, como periodista, en el mismo diario en que participaba su padre, pero también en ensayos - y muy notables--, sobre diversos aspectos de la cultura que interesaban a su curiosidad insaciable y bien dirigida. Amante de la música, de la que tenía una buena formación e información, y del teatro, por el que reveló siempre un singular entusiasmo, su labor periodística la encauzó - la mayor parte de las veces-- hacia la crítica de estas artes. Sus crónicas al respecto merecen especial recuerdo. Frecuentemente, por tales capacidades, fue invitado a disertar sobre algunos de estos temas. Así nacieron dos pequeños folletos, En torno a Juan Sebastián Bach (1927) y Góngora y la nueva poesía (1927), de dos conferencias suyas. Pero su trabajo literario más notable es su contribución a la Revista de Avance, donde publicó ensayos fundamentales, como "Conocimiento de Martín, luego recogido en su libro más conocido: Defensa del Hombre (1937), del cual puede leerse un comentario más amplio en las Actas del Sexto Congreso de la Asociación Internacional de Hispanistas ${ }^{17}$.

Pese a todo esto, en mi opinión, el ensayo de más envergadura que escribió Ichaso fue el titulado Lope de Vega, poeta de la vida cotidiana (1935). Fue premiado, con amplias razones, al convocarse un concurso sobre el tema con motivo del tricentenario de Lope. Leer este ensayo es un verdadero placer. La tesis que toda pieza ensayística debe sostener se desarrolla con galanura de estilo, con riqueza de información en las fuentes y - yo diría - con cierto sabor poético. Además, se revela el profundo conocimiento que tenía Ichaso de la copiosísima obra del Fénix de los Ingenios. Y resalta en todo el estudio el alma y el espíritu de lo mejor de Francisco Ichaso ${ }^{18}$.

La promesa literaria que el ensayista representaba quedó en gran medida truncada por su dedicación al periodismo, para el que tenía grandes dotes, y, sobre todo, por su absorción en la política del país, que llegó a ocupar gran parte de su vida. Así, fue miembro de la Asamblea Constituyente de 1939 -como Mañach y Marinello - , que produjo ese avanzado documento conocido como la Constitución de 1940. Luego fue miembro del Congreso de la República, como sus compañeros Mañach y Marinello. Y siempre estuvo integrado a la política nacional.

Un comentario sobre su obra debe reiterar lo dicho. Fue Ichaso un excelente periodista y ensayista a quien, lamentablemente, sus otros queha-

${ }^{17}$ Rosario Rexach, «Los ensayistas de la Revista de Avance: Francisco Ichaso». Actas del Sexto Congreso Internacional de Hispanistas celebrado en Toronto, 1977. La publicación es de 1980, pp. 593-596.

${ }^{18}$ Francisco Ichaso, Lope de Vega, poeta de la vida cotidiana (La Habana, 1935). 
ceres alejaron del hacer literario, donde estaba llamado a brillar con inusitada luz. Pero que, con lo que ha dejado, es ya un claro exponente de sus valores como ensayista.

La última figura de la que nos ocuparemos es la de Félix LizASO GonZÁlez (Cuba, 1891; Estados Unidos, 1967).

Como ya se ha dicho, entró Lizaso en la Revista de Avance como co-editor, al abandonar la empresa Martí Casanovas. Había sobradas razones para ello, pues aunque no había hecho estudios formales en la Universidad —él se proclamaba autodidacta - estaba capacitado como pocos para la tarea. Era, además, hombre de gran sensibilidad y de inusitada laboriosidad, que se había enamorado de los ideales del Grupo Minorista, del que formó parte. Y que, como la mayoría de sus integrantes, cayó también bajo la fascinación de Martí. Y puede decirse que en cuerpo y alma dedicó su vida a estudiarlo, a divulgarlo, a promover su publicación, a editarlo con gran cuidado y amor, como se hizo patente en aquella primorosa edición facsímil de las cartas de Martí a María Mantilla y sus hermanos, que tituló - muy apropiadamente-Cartas a una niña. En esta tarea no cejó Lizaso en toda su vida. Una bibliografía de todo lo que hizo para honrar al «Mártir de Dos Ríos» ocuparía páginas y páginas. Pero lo que culminó esta devoción fue su muy celebrada - y por múltiples razonesbiografía de José Martí, ya mencionada: Martí, místico del deber. Es una biografía extensa y documentada en la que el autor parte de la tesis de que Martí, más que un hombre, fue un «místico del deber», llevando su argumento a extremos que ciertos datos biográficos parecen no confirmar. El motivo de la tesis es noble y más noble aún el modo de argumentarla. El libro es una gran biografía, aunque, a veces, se fuercen los hechos para reforzar la proposición de que se parte. Esta biografía ha devenido clásica, y junto a la de Mañach, las que gozan de mayor difusión y estima.

Además de esta labor, Lizaso realizó otros trabajos de importancia. Entre ellos hay que citar, y otra vez refiriéndose a su pasión martiana, su labor en los Archivos de José Martí, cuya publicación cuidaba con gran celo. Y a esto añádase su Panorama de la cultura cubana (1949). El libro reúne las conferencias dictadas en Buenos Aires en 1946 gracias a las gestiones de su amigo Antonio Aíta. La obra es sumamente interesante. Llama la atención que en los capítulos dedicados al siglo XIX, en casi ningún momento, se detiene en lo estrictamente literario, sino en lo que tiene que ver con el pensamiento. De ahí que de este siglo destaque, con muy extensos y bien documentados capítulos, las figuras de Varela, José de la Luz y Caballero, Enrique José Varona y, por supuesto, la de José Martí. Al ocuparse de los temas señalados no olvida hacer referencias a Domingo Delmonte y al maestro de Martí, el poeta don Rafael Mendive, 
de quien dice: «Mendive va a ser también un esforzado y constante animador de la cultura cubana» ${ }^{19}$. Confieso que leyendo este libro, sin duda valioso, me ha intrigado siempre este no referirse a lo estrictamente literario en el siglo XIX, y no he hallado explicación al hecho. Pues si el pensamiento es, sin duda, parte de la cultura, también lo es la creación literaria. Y tan debe de haber sido así para el propio Lizaso, que en los dos capítulos que dedica al siglo XX titulados «Panorama de la República», se referirá frecuentemente a ello. Pues en dichos capítulos se encuentran referencias a revistas literarias como El Fígaro, La Habana Elegante, Azul y Rojo y Letras. Pero lo más interesante de esta parte son las noticias que nos da de la fundación de la Biblioteca Nacional (1901) y el dato que nos ofrece sobre la dama cubana Pilar Arazosa de Müller, que donó la imprenta que hizo posible la publicación de la Revista de la Biblioteca Nacional. También nos dice cómo se fundó la Editorial Trópico, que fue - puede decirsela editorial de esta generación, junto con la de la Revista de Avance. Por el interés que tiene para la investigación literaria, copio el párrafo. Dice:

En 1935, de acuerdo con el fraternal compañero Dr. Emeterio S. Santovenia y con la colaboración de Pánfilo D. Camacho, concebimos la organización de una Editorial (sic) con miras a buscar facilidades para el escritor cubano, pero, principalmente, con el anhelo de emprender la edición de las obras completas de Martí. Para este empeño contamos con la cooperación de Gonzalo de Quesada y Miranda, quien recibió de manos de su padre, aquel amigo predilecto de Martí, los escritos que éste le confiara como su albacea literario, y ha actuado como director de la edición de Martí ${ }^{20}$.

Son valiosas igualmente las referencias a distintas instituciones culturales, como el Lyceum, la Institución Hispano-Cubana de Cultura y otras. Así como la noticia acerca de cómo se organizó la Dirección de Cultura, dentro del Ministerio de Educación, que narra de este modo:

Un hombre que había formado en la Protesta de los Trece, en el Grupo Minorista y en la «revista de avance», Jorge Mañach, estructuró desde la Secretaría de Educación un organismo capaz de llevar a sus más altas consecuencias los beneficios de la cultura. En 1934 surgió la Dirección, y surgió con un amplio programa ${ }^{21}$.

Debe añadirse que la primera publicación de dicho organismo fue la conferencia dada en La Habana por Gabriela Mistral, titulada «La lengua

${ }^{19}$ Félix Lizaso, Panorama de la cultura cubana (México: Colección Tierra Firme, 1949), p. 60 .

${ }^{20}$ Ibid., p. 141,

${ }^{21}$ Ibid., pp. 137-138. 
de Martí», que vino así a ser el primero de los Cuadernos de Cultura. Regentaba el Departamento don José María Chacón y Calvo, con la muy diligente y eficaz colaboración de Lizaso.

Por lo que aquí se ha expuesto, se comprueba cómo fue Félix Lizaso un miembro destacadísimo de su generación, que trabajó intensamente por la cultura cubana con el respeto y la estimación de todos. Tenía verdadera curiosidad intelectual y una paciencia y tesón inquebrantables para la investigación documental que se hace explícita en sus obras. Pero su gran labor, la que le consagra dentro del marco de la literatura cubana, es su devoción por Martí, de la que dejó abundantes y bien documentadas muestras, como se ha señalado.

$\mathrm{Y}$ antes de cerrar este trabajo es necesario decir que esta generación - como todas - tiene dos vertientes: la primera, que se prolonga hasta el momento en que se promulga la Constitución de 1940, que es de la que se ha tratado aquí, y la segunda, la de los epígonos, que termina su vigencia activa alrededor del momento en que se da el golpe de Estado en 1952, cuando termina el régimen constitucional y democrático en Cuba. Esta última vertiente de la segunda generación republicana, a la inversa que la anterior, pone poca atención al menester político. Sus miembros rara vez pertenecen al periodismo y su figura central es José Lezama Lima y el grupo que se reúne en torno a Orígenes. Todos se adhieren a una literatura de muy diverso calibre a la que practicaron los miembros de la primera falange de dicha segunda generación republicana. Su onda estética es más elitista, menos al alcance de las grandes mayorías, y no por especial deseo de sus participantes, sino porque la literatura que practican requiere una minoría cultivada, al tanto de las nuevas corrientes estéticas que priman para la escritura.

Y todavía otra salvedad hay que hacer. Se dijo muy al principio de este trabajo, y se fundamentó en un juicio de Max Henríquez Ureña, que la segunda generación republicana no había sido una generación de novelistas. Así es, pese a pertenecer a dicho grupo Alejo Carpentier. Se explican en seguida las razones. Sin contar con que el propio novelista escribió que la novela era un «género tardío», tanto en lo personal como en lo históricosocial, hay que admitir que lo que escribió Carpentier durante la vigencia de la primera parte de dicha generación (1923-1940) fue sólo Ecué-Yamba$O$ (1933), que el propio autor desestimó y alguna vez intentó retirar de la circulación. No fue hasta después de la publicación de $E l$ reino de este mundo (1949) cuando llegó el gran novelista que todos conocemos; sobre todo, después de El Siglo de las Luces, de 1959. Entrar a dilucidar las razones de este hecho no es el tema de este trabajo. Pero quede señalado, 
así como que durante la vigencia de la generación estudiada apareció un novelista singular, Enrique Labrador Ruiz (Cuba, 1902 ...), cuyas novelas «gaseiformes» merecen consideración, así como la del cuentista Lino Novás Calvo titulada El Negrero.

Con lo anterior termina este breve recuento de lo que fue la segunda generación republicana en Cuba en su período inicial. Si hubiese que hacer un balance de lo que logró, podría resumirse en estos hechos: apertura al mundo europeo e hispanoamericano, con la consiguiente superación del provincianismo cultural; fundación de la Revista de Avance como órgano de las nuevas ideas; revelación de Martí en lo biográfico y en su obra, y, finalmente, la abolición de la «enmienda Platt», lograda por el pueblo de Cuba con el apoyo de todas las minorías dirigentes, principalmente con la de los integrantes del Grupo Minorista. También producto de esta generación fue la Constitución de 1940. Como saldo de la labor de una generación no es poco. Quede consignado.

Nueva York, 16 de diciembre de 1988. 
